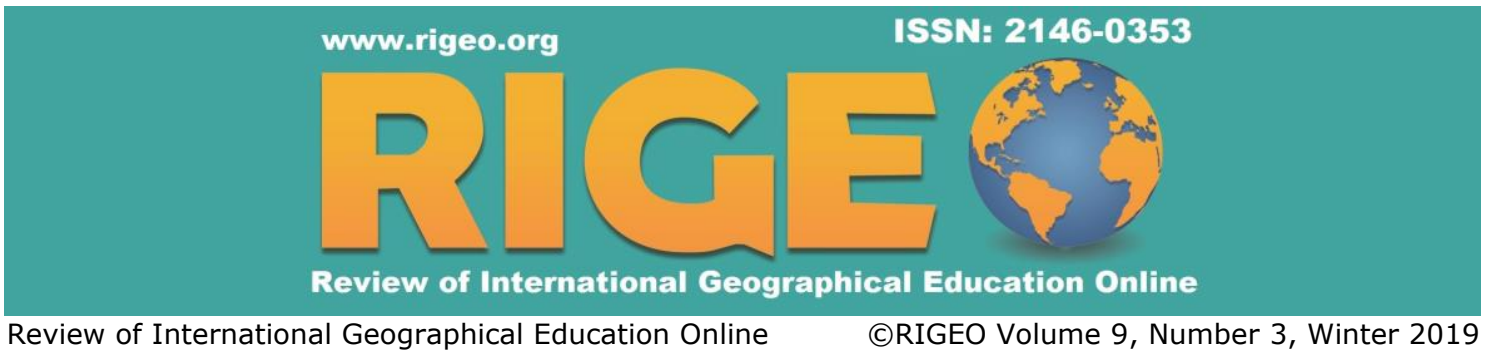

Research Article

Copyright @ RIGEO 2019

To cite this article: Jitmahantakul, S.; Chenrai, P. (2019). Applying Virtual Reality Technology to Geoscience Classrooms. Review of International Geographical Education Online (RIGEO), 9(3), 577-590. Retrieved from http://www.rigeo.org/vol9no3/Number3Winter/RIGEO-V9-N3-5.pdf

DOI: 10.33403/rigeo.592771

Submitted: July 216, $2019 \quad$ Revised: November 11, $2019 \quad$ Accepted: December 5, 2019

\title{
Applying Virtual Reality Technology to Geoscience Classrooms
}

\author{
Sukonmeth JITMAHANTAKUL ${ }^{1}$ \\ BASE STAR, Chulalongkorn University, THAILAND \\ Piyaphong CHENRAI ${ }^{2}$ \\ BASE STAR, Chulalongkorn University, THAILAND
}

\begin{abstract}
Applying virtual reality (VR) technology to geoscience classrooms provides a new way to engage students. Visualizing geological information in 360-degree allows students to experience processes of the Earth and makes them feel like they are outside the classroom. This paper describes a convenient technique for making 360-degree VR environments specifically for geoscience classrooms. In comparison to traditional classrooms, this teaching method enables students to more easily comprehend how geological features occur in nature through a series of 360-degree outcrop scenes and 360-degree infographic images. The learning from using this VR environment in geoscience classrooms at the high-school level is assessed. Results from three different high schools show that the learning gain of students is improved by $22-28 \%$ and the overall average post-test scores are significantly higher than pre-test scores at the $\mathrm{p}=0.05$ level after using the VR environment in the classrooms. This technique could potentially benefit any science classroom and have applications in other disciplines requiring similar visualization techniques.
\end{abstract}

\section{Keywords}

Virtual reality; Geoscience; Geoscience Education; Learning gain; Classroom; Smartphone

In geoscience education, classroom instruction often relies mainly on textbooks, paper maps and outcrop photos. Many students have difficulty recognizing and interpreting real-world spatial relationship from those traditional teaching media because most geological phenomena require spatial visualization and object

\footnotetext{
${ }^{1}$ Asst. Prof. Dr., Basin Analysis and Structural Evolution Special Task Force for Activating Research (BASE STAR), Department of Geology, Faculty of Science, Chulalongkorn University, Bangkok 10330, Thailand

${ }^{2}$ Corresponding author: Asst. Prof. Dr., Basin Analysis and Structural Evolution Special Task Force for Activating Research (BASE STAR), Department of Geology, Faculty of Science, Chulalongkorn University, Bangkok 10330, Thailand

(C) Review of International Geographical Education Online

RIGEO 2019

ISSN: 2146-0353

www.rigeo.org
} 
visualization abilities (Stieff et al., 2005; Whitmeyer et al., 2009; Kastens, 2010). Twodimensional (2-D) media are only a result of two- to three-dimensional (3-D) transformation onto a graphic paper or projector screen. They often cannot demonstrate the extent of landscapes and geological features in three-dimensions and also do not improve student's spatial visualization ability (Stieff et al., 2005). It is important for teacher to use new technology to present geological features in the form that is convenient for student to develop spatial thinking.

Generally, geological field trips are seen as necessary components of geoscience education that facilitate understanding geological structures and forms, geological materials from different geodynamic processes, depositional environments, and records from sediments and fossils (Elkins and Elkins, 2007; King, 2008; Esteves et al., 2013; Martínez-Graña et al., 2014). However, geological field trips in schools have decreased in the number around the world due to financial constraints (Welsh and France, 2012; Leydon and Turner, 2013; Dolphin et al., 2019). Consequently, field trips in geoscience today can be less costly by utilizing technology and digital information (Hurst, 1998; Arrowsmith et al., 2005; McCaffrey et al., 2005; Bailey et al., 2012; Fuller, 2012). Nowadays, computer technology offers alternatives to traditional classroom instruction. Since the 2000s, computer-based Virtual Field Trips (VFTs) have been developed as an alternative to the actual field trips. Although, there are a lot of advantages of the VFTs for geoscience teaching, the VFTs can also have disadvantages as they cannot simulate many of the real sensory aspects of fieldwork (Qui and Hubble, 2002). However, it is possible to create very advanced VFTs, which will be able to replace the actual field trips (Çaliskan, 2011). Meagher et al. (2018) reported that computer-based image training of rock classification can provide a useful supplement to physical rock training. The development of the internet and mobile phone technologies rapidly increased in the previous decade (Kaplan and Haenlein, 2010). Hence, students and mobile phones are virtually inseparable in modern student life. The use of portable hardware such as tablets, personal computers and recently also smartphones and iPads enables more convenient ways for teachers to interact with students (e.g., sharing information or game-based teaching). Furthermore, technological developments have provided new tools and techniques to support interactions between students and smartphones in classrooms (e.g., Google Expeditions, HP Reveal and Virtual Reality). Virtual reality (VR) is sometimes referred to a hybrid reality because it merges real and virtual worlds to produce new environments and visualizations where physical and digital objects coexist and interact in real time (Liou and Chang, 2018). While, geological outcrop accessibility and geological field trips can be difficult to manage with many students in one group or students with disabilities to participate in geoscience field trips (Gilley et al., 2015). VR technology makes it possible to visualize geological objects/features on almost any personal computer and/or smartphone screen.

A VR environment for geoscience instruction can be constructed using webdistributed tools such as Google applications, as this paper reports. The use of VR environments, especially with mobile devices, can remove limitations and provide benefits for geoscience classrooms. 
This paper describes a technique where VR environments are placed over a mobile device's view of the real world and displayed geological features to classrooms (Figure 1). Students can see and move around as though they are real within classrooms. Although this paper focuses on geoscience classrooms, this technique could potentially benefit any science classroom and have applications in other disciplines requiring similar visualization techniques.
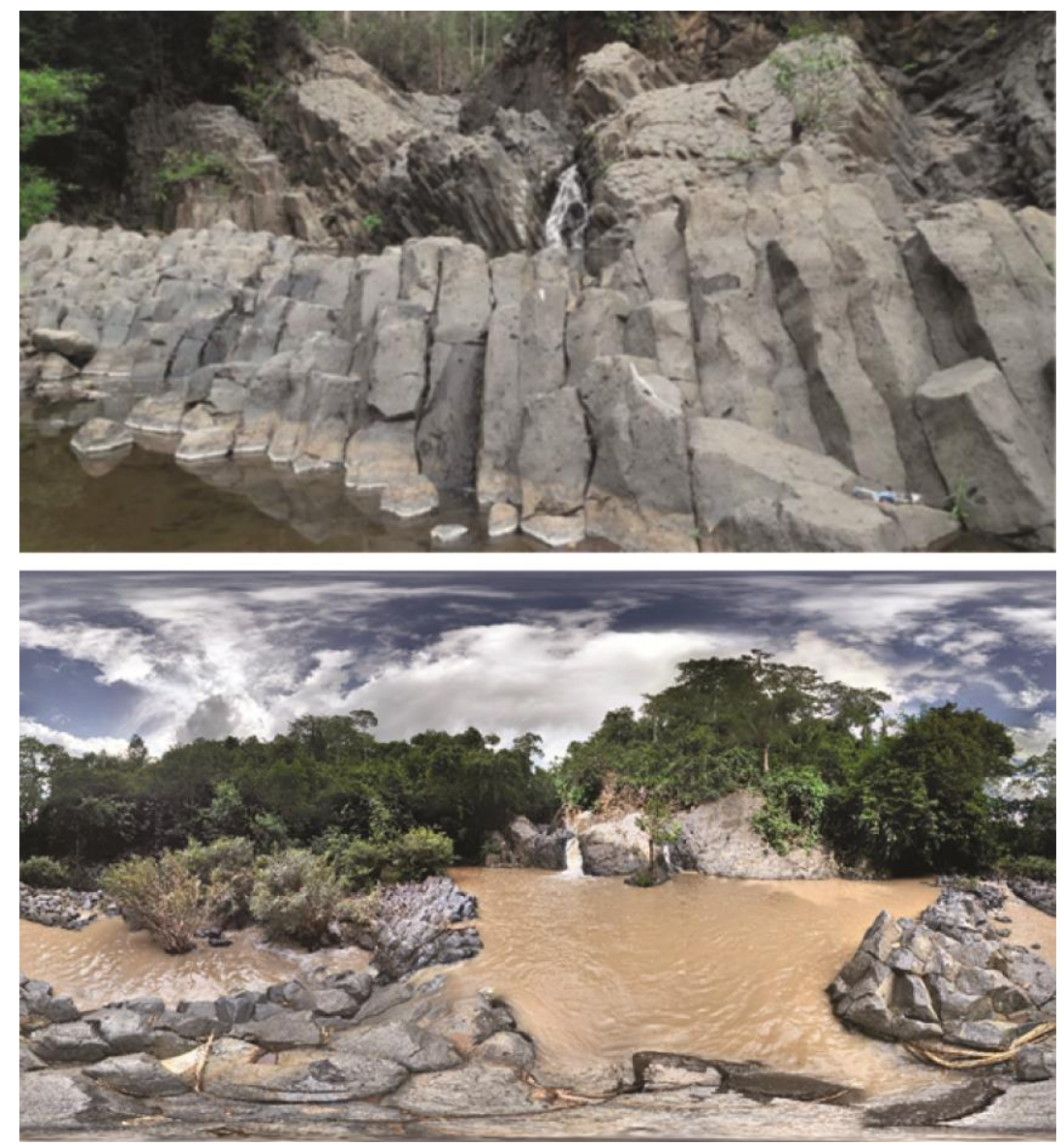

Figure 1. (Above) Photograph of columnar basalt in Thailand taken from the science textbook by the Institute for the Promotion of Teaching Science and Technology (IPST). Note: The field of view is limited. (Below) A 360-degree photo of the same outcrop shows a wider-angle view of the area. Students can use this 360-degree photo to observe more geological features in the VR environment via Google Tour Creator than from the printed photograph in the textbook.

Similar to the rest of the world, traditional teaching methods which include lectures by the teacher, assigned textbook readings, whole class discussion, and a review of the textbook topics at the end of each teaching unit, are commonly used in many Thai schools. The motivation of this study is that geological field trip is a necessary component of geoscience education and cannot be brought to traditional geoscience classrooms. The essence of virtual geological environments is to capture the real world environment of a specific location or region through a collection of data, photographs, cartography and other information without the cost of physically being there (Carmichael et al., 2013; Dolphin et al., 2019). This way of learning is a key concept 
behind the educational benefits of using virtual field trip in geoscience education. VR technology can help to understand geological processes and fundamental concepts to students. The current VR technology allows the creation of 360-degree photos, 360degree images, and diagrams, which enable the teaching of complex concepts through visual demonstrations. Then, students can view the virtual geological features as though they were peering at the geological feature itself. This study attempts to create a new method for teaching in geoscience classrooms using modern VR technology and to measure learning gains of students as a result of using the VR environments created from this study. Thus, the challenge of this study to geoscience education is to bring geological features and processes to classrooms.

\section{Methodology}

VR technology opens up many opportunities for scientific visualization in many areas of sciences and can be used as a teaching media. Many VR devices and applications have been successfully built and several have been deployed and commercialized (Ma et al., 2018). The majority of VR systems run on handheld computing devices, such as tablets and smart phones that almost become commonplace in many schools around the world. VR technology for education is simple and accessible via internet or "Wi-Fi" with smartphones at schools.

Recently, teachers and demonstrators can create a VR environment using a free, online, advanced, and virtual reality tools such as Google Tour Creator with 360-degree photos from geological outcrops. In addition, geological theories or concepts that cannot be seen in real environments such as geological hazards or earth structures, infographic images and diagrams could be used instead of 360-degree photos taking from real environments. These visualizations could aid teachers in explanation of events or structures that are not commonly visible in real life. It is also possible to build a series of geological features at different scales and locations for the same target or same learning objectives allowing students to compare geological processes at different places and scales, e.g., from outcrop scale to micro scale.

This research was conducted as a quasi-experimental design using a one-group preand post-test construction. This study took student groups from three different high schools in Thailand during the beginning of the school year as a study population in 2018. The groups all used the same learning methods of using VR environments as teaching media to enhance learning in geoscience classrooms. The learning objectives in the VR environments in this study are adapted from the Institute for the Promotion of Teaching Science and Technology (IPST), Thailand (Table 1). 
Table 1

The learning objectives in the VR environments in this study are adapted from the Institute for the Promotion of Teaching Science and Technology (IPST), Thailand. The learning objectives shown here are English translations of the actual learning objectives in Thai.

\begin{tabular}{|c|c|c|}
\hline No. & Learning objectives & $\begin{array}{l}\text { Number } \\
\text { of tours }\end{array}$ \\
\hline 1. & $\begin{array}{l}\text { Explain the stratification and properties of the Earth structure with examples } \\
\text { of supporting information. }\end{array}$ & 2 \\
\hline 2. & Explain the geological evidences that support plate tectonics theory. & 3 \\
\hline 3. & $\begin{array}{l}\text { Identify and explain the causes of different types of plate boundaries with } \\
\text { examples of geological evidences found. }\end{array}$ & 4 \\
\hline 4. & $\begin{array}{l}\text { Analyze geological evidences and explain the geological events of the } \\
\text { designated area. }\end{array}$ & 15 \\
\hline 5. & $\begin{array}{l}\text { Explain the cause of the volcanic eruption process and the factors that cause } \\
\text { the intensity of eruptions and the different shapes of the volcano, including } \\
\text { searching for risky areas, designing, and presenting guidelines for monitoring } \\
\text { and keeping yourself safe. }\end{array}$ & 3 \\
\hline 6. & $\begin{array}{l}\text { Explain the cause, process, intensity, and magnitude of the earthquake, } \\
\text { including searching for risky areas, designing, and presenting guidelines for } \\
\text { monitoring and keeping yourself safe. }\end{array}$ & 5 \\
\hline 7. & $\begin{array}{l}\text { Explain the cause of the tsunami formation, including searching for risky } \\
\text { areas, designing, and presenting guidelines for monitoring and keeping } \\
\text { yourself safe. }\end{array}$ & 4 \\
\hline 8. & $\begin{array}{l}\text { Identify mineral types, analyze mineral properties, and describe benefits of } \\
\text { mineral resources. }\end{array}$ & 5 \\
\hline 9. & $\begin{array}{l}\text { Identify rock types, analyze rock properties, and describe benefits of rock } \\
\text { resources. }\end{array}$ & 15 \\
\hline 10. & $\begin{array}{l}\text { Explain the process of petroleum and coal explorations by using geological } \\
\text { data. }\end{array}$ & 4 \\
\hline 11. & $\begin{array}{l}\text { Describe the product properties obtained from petroleum and coal } \\
\text { production, and propose an appropriate utilization. }\end{array}$ & 1 \\
\hline 12. & $\begin{array}{l}\text { Interpret the information from geological map, geographic map, and } \\
\text { topographic map of the designated area. }\end{array}$ & 4 \\
\hline
\end{tabular}

\section{Development and Design of VR environments}

The development and design of the VR environments described in this paper targets smartphone enthusiasts because the student communities are most likely to be using their mobile devices in informal learning. 360-degree photos were shot by a 360-degree panoramic camera with two $190^{\circ}$ wide-angle fish eye lenses. Each photo has a $2: 1$ aspect ratio and resolutions of 6912 pixels wide x 3456 pixels high (or 23.88 Megapixels). In some areas, 360-degree photos were created using a smartphone via Google Street View application. This application is affordable and easy to use but requires practice to avoid mismatched stitches.

Google Tour Creator has emerged as one of the most powerful and easy-to-use tools for viewing, observing and analyzing geological features, processes, and events. Google Tour Creator is a computer software that integrates 360-degree photos or images to 
create a VR environment. Users can easily view and share their own data on Google Tour Creator. The choices of data input into this software can adopt to various types of data such as photo or image. Thus, users could organize input data from field photos and infographic images directly into this software depending on the learning objectives of the course.

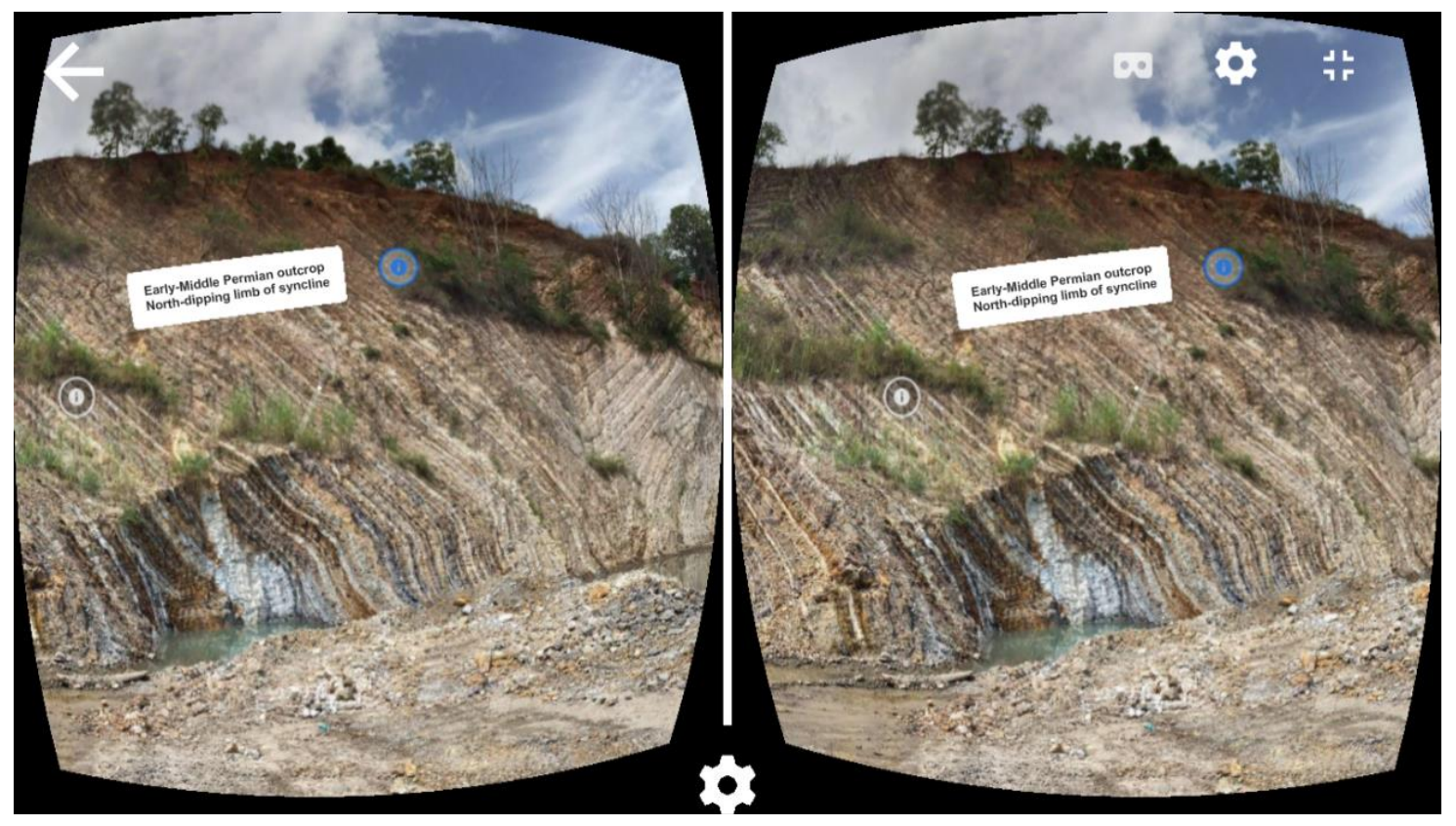

Figure 2. A screenshot from smartphone displays the VR view of the Early-Middle Permian outcrop in Lopburi Province, Thailand. In Google Tour Creator, any geological feature can be marked on the scene as a point of interest (i) with descriptions shown when users click on the point.

Location selection is a significant process for demonstration in geoscience classrooms using VR technology. 360-degree photos give viewers the ability to see in all directions, hence small geological features may be not detected in the photos. 360degree photos or VR environments also allow viewers to access the locations that are normally inaccessible, such as geological hazard areas or the places that are too far away or too small for a group to visit. Thus, VR environments could build on this approach, providing viewers a more interesting experience. The requirements for a geological outcrop to make VR environment should include an ability to display geological information clearly and accurately and to show enough open space for observation within the surrounding area.

After locations were selected, geological outcrops or so called "geosites" can be displayed the geological features to classrooms. An interesting point placed in VR scene can be represented a question, activity, and/or explanation, which is available in the Google Tour Creator (Figure 2). The different interesting points are created in VR views to develop the most appropriate point to correspond with geological contents taught in actual geoscience classes. All VR information at the geosites can be read and seen by moving head around 360-degree. 
After a satisfying image of a 360-degree format was produced, the final extent of VR environments was defined tour and scene using learning objectives for geoscience classrooms within Google Tour Creator. Thereafter, in the tour, 360-degree environments were created which depicted geological information for teaching in classrooms. The final outcome of the construction VR environments in this study was a digital quick response $(\mathrm{QR})$ code that links to the tour for students or teachers to use easily. In this study, 53 tours from many places in Thailand are created to use in geoscience classrooms based on the learning objectives from IPST, Thailand (Table 1). It should be noted that the learning objectives shown in Table 1 are English translations of the actual learning objectives in Thai. The number of the tours is different depended on how the learning objectives fit with the geosites. These VR environments can be shared with anyone via internet using mobile devices (smartphones, tablets). Figure 3 summaries a typical workflow for constructing a virtual geological environment.

(a) 360-degree photography

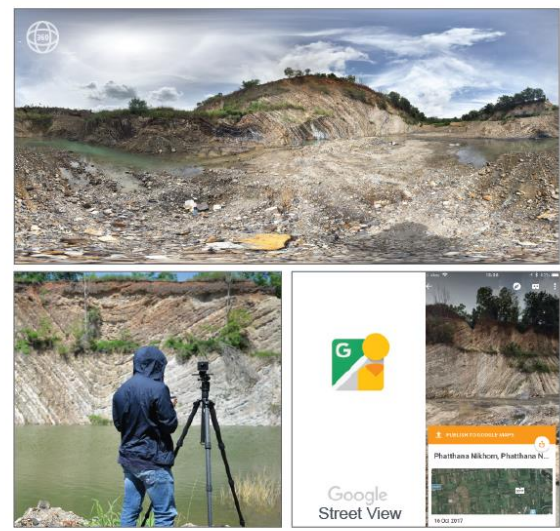

(c) VR tour creator

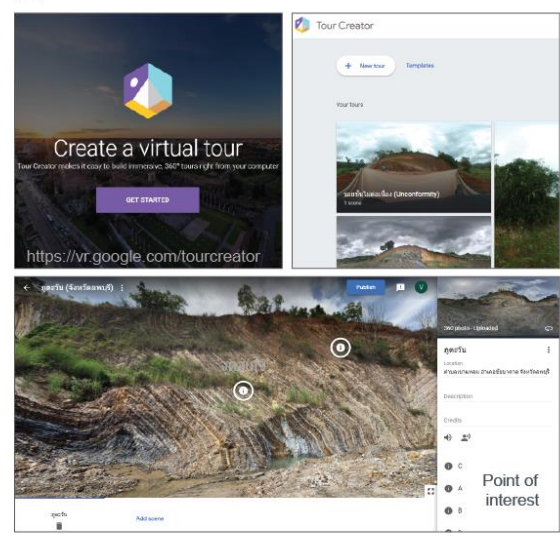

(b) 360-degree infographic design

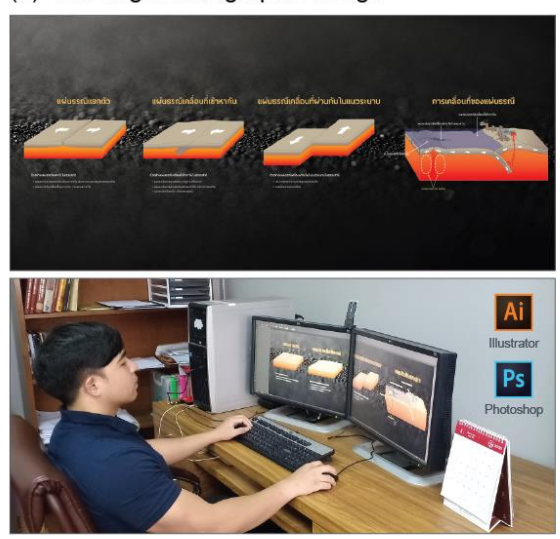

(d) Share and access VR tour via QR code

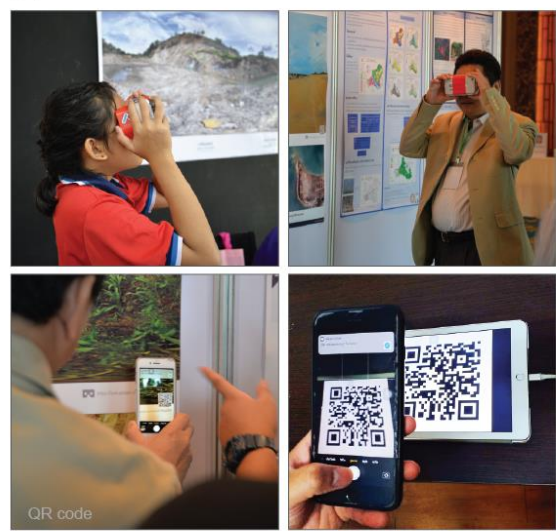

Figure 3. A typical workflow for constructing a virtual geological environment. (a) 360-degree photography of the outcrop using a 360-degree panoramic camera or Google Street View application on smartphone. (b) 360-degree infographic design of conceptual geological models using computer graphic software. (c) VR tour creator by uploading both 360-degree photos and 360-degree images as scene to Google Tour Creator website. Each scene can be annotated by adding points of interest with short description explaining geological features. (d) The finished scene can share and access via QR code using smartphone and VR goggle. 


\section{Study Population}

In total, 93 students from three different high schools participated in learning activities using the VR environments for geoscience classrooms. The three different schools are selected based on the score ranking of the ordinary national educational test (ONET) in Thailand which is low, medium and high ranks, namely school A, B, and C, respectively in this study. The students in three different schools have no previous experience on VR environments before testing the VR environments in this study. The students enrolled in these three high schools are selected by a cluster random sampling method. The population is grade ten students and is in a gender-balanced mix classroom in these three high schools. The participated students from the high school A, B and C are 31 students ( 58 per cent male, 42 per cent female), 38 students ( 42 per cent male, 58 per cent female), and 24 students (66 per cent male, 34 per cent female), respectively. The treatment is in the form of learning activity using the VR environments. The teaching process in this study comprises of a lecture and an exercise during 2 hours in a geoscience class. The two teachers who give a lecture and an introduction of the VR environments are the same persons for all three high schools and are from this research team.

\section{Implementation of VR Environments in Classrooms}

In this study, different tours with mixed scenes of different learning objectives were created to enable teachers and students to access the VR environments with geological information of each geological outcrop (Figure 2). Only 4-5 tours (360-degree photos and infographic images) are used to test in the classrooms for this study due to time limitation for 2 hours. The learning activities are conducted during a lecture class when a teacher needs to show an example of geological features. Then, the teacher uses the VR environments as teaching media instead of textbooks.

The learning activity starts with a short introduction for using the geological virtual environments in the classrooms. The students are informed that there will be a test before and after the learning activity and their results will be part of this study to evaluate students' learning gains. During the lecture, every 15 minutes, students are asked to use the VR environments and answer a key question related to the learning objectives that they have learned from the lecture. The questions should encourage students to apply, summarize, explain or identify an important aspect or a geological feature presented in the VR environments. For example, the students are asked to identify the geological feature and rock type that are presented in the VR environment of the columnar basalt (Figure 1) and asked students to explain how the columnar basalt form. In addition, teachers can engage students into a discussion during the learning activity aimed at observation the geological features within the VR environments.

After the end of observation, students are asked for volunteers or called on a randomly selected student to respond or discuss the question. Each learning activity should spend $20-25$ minutes, then the teacher continues a lecture for the next learning objectives and repeats the same learning activity but change the VR environments according to the learning objective. The learning activities are focused on: 1) be familiar with a geological virtual environment, 2) be able to observe common geological 
features, and 3) be able to analyze, describe, and discuss the geological events such as geohazard or depositional environment. At the end of the learning activity teachers should initiate and guide a short discussion, support hypothesis finding from student discussion and give the classroom for reflections and/or feedbacks of students' discussions.

The learning activities with the VR environments require that students have to use their own smartphone and internet/Wi-Fi in order to access to Google Tour Creator. Then students place their smartphones in a VR cardboard to create a $3 \mathrm{D}$ effect holding up to their eyes. Apart from that, no other equipment is needed. If VR cardboards or smartphones are limited, students can work with their partners, preferably not exceeding three students.

\section{Data Collection and Evaluation}

The data collection came from pre- and post-test in order to assess student learning gains for the use of the VR environments in geoscience classrooms, participated students were asked to do pre- and post-test with a multiple choices comprising 20 questions which is the same test before and after the learning activities.

The pre- and post-test was designed based on the revised bloom' taxonomy to assess the course learning objectives (Anderson and Krathwohl, 2001). In addition, the preand post-test was sent to 3 geoscience experts including 2 geoscientists and 1 educationist to check the quality and content validity by using the index of itemobjective congruence (IOC) measurement. The IOC is used to evaluated the multiple choice questions of the pre- and post-test based on the score range from -1 to +1 , congruent $=+1$, questionable $=0$, and incongruent $=-1$. The questions that have scores lower than 0.5 are revised. On the other hand, the questions that have scores higher than or equal to 0.5 were reserved. The results of indices of item-objective congruence (IOC) for the pre- and post-test used in this study. The multiple choice questions were used to evaluate the VR environment created from this study because the teaching time during the test is limited for only 2 hours. It was also not enough time for group discussion, self-reflecting essays or other means.

Pre-test was conducted in order to seek out the initial scores, or capability, of students before the learning activities. Post-test was conducted in the end of the learning activities in order to find out the learning gains of the students by using the VR environments in geoscience classrooms. The method used to assess student learning gains in this study is based on Hake (1998). The statistical tools calculated from the preand post-test are basic statistics including average, standard deviation, and the difference of score between before and after class (T-Test).

\section{Findings and Discussion}

The new way of geoscience teaching is successfully able to create the virtual geological environments in this study. The basic statistics from pre- and post- test of using the VR environment in geoscience classrooms from students in three different high schools are shown in Table 2. From t-stat values, it can be seen that there are a significant difference between the average pre- and post-test scores from all three high 
schools after using the VR environments, $(\mathrm{t} 0.95,23=1.71, \mathrm{t} 0.95,30=1.70$ and $\mathrm{t} 0.95,35$ $=1.69)$. The overall average post-test scores from three high schools are significantly higher than pre-test scores at $\mathrm{p}=0.05$ level after using the VR environments designed from this study.

Table 2

Comparison of the three schools with overall test averages.

\begin{tabular}{|c|c|c|c|c|c|}
\hline \multirow{2}{*}{$\begin{array}{c}\text { Learning objective } \\
\text { test }\end{array}$} & \multirow{2}{*}{ Mean } & \multirow{2}{*}{ SD } & \multicolumn{3}{|c|}{ t-test dependence } \\
\hline & & & df & t-stat & p-value \\
\hline Pre-test school A & 7.06 & 4.46 & \multirow{2}{*}{30} & \multirow{2}{*}{5.75} & \multirow{2}{*}{0.0000014} \\
\hline Post-test school A & 9.97 & 4.17 & & & \\
\hline Pre-test school B & 7.34 & 2.61 & \multirow{2}{*}{37} & \multirow{2}{*}{9.31} & \multirow{2}{*}{0.00000000002} \\
\hline Post-test school B & 10.18 & 1.51 & & & \\
\hline Pre-test school C & 9.42 & 4.17 & \multirow{2}{*}{23} & \multirow{2}{*}{6.91} & \multirow{2}{*}{0.0000005} \\
\hline Post-test school C & 12.42 & 4.08 & & & \\
\hline
\end{tabular}

The learning gains of using the VR environment in geoscience classrooms from students in three different high schools are shown in Table 3. The use of the VR environment in geoscience classrooms shows that the learning gains of students are improved by $22-28 \%$. The results of average post-test scores in each schools may be different, but it is clearly that every participated student gains new learning after using the VR environments in geoscience classroom.

Table 2

Comparison of the Three Schools with Overall Test Averages

\begin{tabular}{|c|c|c|c|}
\hline Normalized learning gains & \multicolumn{3}{|c|}{ Schools } \\
\cline { 2 - 4 } & A & B & C \\
\hline possible learming gains & & & \\
total score - pre test & 0.224 & 0.225 & 0.283 \\
\hline
\end{tabular}

The learning gains of students used the VR environments in geoscience classrooms as teaching media are assessed from post-test scores. However, a single test after using the VR environments may only assess knowledge of students that were acquired prior to use the VR environments. In addition, students or schools that do well on pre-tests tend to do well on post-tests. For instance, it is likely that students in higher ranked schools would get better post-test scores than students in lower ranked schools, even if no new learning occurred in the test group. Thus, the learning gains should be used to compare student learning among schools or test groups.

Geoscience classrooms in traditional teaching method usually use text book as teaching media. However, the disadvantage of this traditional teaching method is the lack of development skill and interactivity in classrooms. Also, students are often unable to follow teacher's explanations, resulting in many years of geoscience teaching that is sometime ineffectual learning. For example, teachers could help students to understand complex underground structures that cannot be seen. Virtual geological 
environments enable to close-up experience and observation, students are better able to get in touch with the feeling of the presence and fun of learning. In process of observation, students can also rotate and adjust the viewing angle of the geological outcrop for their best visual angle which is totally unattainable by the traditional teaching and learning methods.

There was a consensus that virtual geological environments could reduce the cost of a real geological field trip. Further implementations could extend virtual geological environments to a wider user including geoscientists and even the public. Importantly, this technique could aid in the development of the skills required to understand geological features by non-geologists who simply need concrete examples.

Google Tour Creator is easy to create, but the creator of the tours also needs to consider the user experiences, the geological objects being illustrated, and the learning objectives. Content design is an important consideration for all classrooms used Google Tour or VR environment. Sometimes it might not be appropriate to use an outcrop photo, but in many cases they are a very useful approach if designed appropriately infographic images for geoscience education. Virtual geological environments are not just confined to the terrestrial tier. Teachers can design image materials depended on learning objectives such as terrain of the moon or underwater.

\section{Limitations and Requirements}

A limitation of the virtual geological environments is the lack of student-to-student interactions within the virtual geological environments. This is an important component during real field trips. However, teachers can add questions or "point of interest" within VR scene, so that students can discuss with their friends. In addition, working in pairs or small groups could encourage constructive learning while utilizing VR environment.

Experience of using the virtual geological environments in classrooms in this study shows that using virtual environments can cause "sickness" with symptoms ranging from dizziness, tiredness of the eyes, and headaches. The occurrence of these sickness seems to be dependent on individual student behavior, technical factors, and type of smartphone.

The outcrop examples for a successful geoscience education tool must be capable of showing representative geological structures or features. The field data collection is sometimes problematic with unpredictable weather and inaccessible area. The photo and image file size of a VR environment directly influences the load time of data on smartphone. It seems that geoscience teachers in Thailand, who have geological data or geosites at the school level, do not tend to share knowledge and experiences with others. However, creating a geoscience teacher community may encourage teachers in Thailand to share free and open VR environments to geoscience teachers. In addition, the teaching method proposed in this study requires teachers who be able to adapt and to implement the innovations. Thus, computer and software skills and available tools at schools may be limited to design and develop VR environments for their classes at the high school level. 


\section{Further Applications}

The aim of the virtual geological environment in this paper, has not been to replace the traditional field trip but to introduce students to the fundamental skills needed to understand geological features and processes in classrooms. Moreover, the virtual geological environment can be used in higher education at university scale for geological students reviewing the outcrop environment before going on the 'real' field trip (Hesthammer et al., 2002). Currently, Google application is more common role in science classrooms. In addition, Google Tour Creator can add a voice introduction, through the VR environments, hence students in the VR environments can better understand as a result of the impact of voice. The interactions and dynamic observations of the VR environments, teachers can guide or explain students to learn through the screen so that students can learn several times outside classrooms without a teacher. More studies targeting the develop skill and proficiency of the impact of VR environment in geoscience study are needed as innovative educational strategies are developed.

\section{Conclusion}

This paper presents a convenient and inexpensive method for development of innovative educational strategies in geoscience education that enables the geological outcrop and the geological context into classroom as VR environment. The current VR technique is capable of successfully creating the virtual geological environment for geoscience class rooms. Internet accessibility via smartphone assists students in the visualization of the places where are highly geological interest and highly scientific and educational contents.

The learning gains of using the VR environments in geoscience classrooms of students in three different high schools show that the learning of the students is improved by $22-28 \%$. The overall average post-test scores from three high schools are significantly higher than pre-test scores at the $\mathrm{p}=0.05$ level after using the VR environments designed from this study.

The implementation of this technique has no cost as the software is free and accessible (Google Tour Creator) to schools via internet. Thus, this technique could reduce the cost for real geological field trip. Further implementations could extend virtual geological environments to a wider user including geoscientists and even the public.

\section{Acknowledgements}

The authors gratefully acknowledge the financial support from the Thailand Research Fund (TRF) under Grant Number RDG6140029 and Grants for Development of New Faculty Staff, Ratchadaphiseksomphot Endowment Fund, Chulalongkorn University. Google applications used in this study are thanked for free web opened tools. Anonymous reviewers are thanked for their useful and constructive comments. 


\section{References}

Anderson, L. W., \& Krathwohl, D. R. (2001). A revision of Bloom's taxonomy of educational objectives. A Taxonomy for Learning, Teaching and Assessing. Longman, New York.

Arrowsmith, C., Counihan, A., \& McGreevy, D. (2005). Development of a multi-scaled virtual field trip for the teaching and learning of geospatial science. International Journal of Education and Development using ICT, 1(3), 42-56.

Bailey, J. E., Whitmeyer, S. J., \& De Paor, D. G. (2012). Introduction: The application of Google Geo Tools to geoscience education and research. Geological Society of America Special Papers, 492, 7-19.

Çaliskan, O. (2011). Virtual field trips in education of earth and environmental sciences. Procedia-Social and Behavioral Sciences, 15, 3239-3243.

Carmichael, P., \& Tscholl, M. (2013). Cases, simulacra, and Semantic Web technologies. Journal of Computer Assisted Learning, 29(1), 31-42.

Dolphin, G., Dutchak, A., Karchewski, B., \& Cooper, J. (2019). Virtual field experiences in introductory geology: Addressing a capacity problem, but finding a pedagogical one. Journal of Geoscience Education, 67(2), 114-130.

Elkins, J. T., \& Elkins, N. M. (2007). Teaching geology in the field: Significant geoscience concept gains in entirely field-based introductory geology courses. Journal of geoscience education, 55(2), 126-132.

Esteves, H., Ferreira, P., Vasconcelos, C., \& Fernandes, I. (2013). Geological fieldwork: A study carried out with Portuguese secondary school students. Journal of Geoscience Education, 61(3), 318-325.

Fuller, I. C. (2012). Taking students outdoors to learn in high places. Area, 44(1), 7-13.

Gilley, B., Atchison, C., Feig, A., \& Stokes, A. (2015). Impact of inclusive field trips. Nature Geoscience, 8(8), 579.

Hake, R. R. (1998). Interactive-engagement versus traditional methods: A six-thousand-student survey of mechanics test data for introductory physics courses. American journal of Physics, 66(1), 64-74.

Hesthammer, J., Fossen, H., Sautter, M., Sæther, B., \& Johansen, S. E. (2002). The use of information technology to enhance learning in geological field trips. Journal of Geoscience Education, 50(5), 528-538.

Hurst, S. D. (1998). Use of "virtual" field trips in teaching introductory geology. Computers \& Geosciences, 24(7), 653-658.

Kaplan, A. M., \& Haenlein, M. (2010). Users of the world, unite! The challenges and opportunities of Social Media. Business horizons, 53(1), 59-68.

Kastens, K. (2010). Commentary: Object and spatial visualization in geosciences. Journal of Geoscience Education, 58(2), 52-57.

King, C. (2008). Geoscience education: An overview. Studies in Science Education, 44(2), 187222.

Leydon, J., \& Turner, S. (2013). The challenges and rewards of introducing field trips into a large introductory geography class. Journal of Geography, 112(6), 248-261.

Liou, W. K., \& Chang, C. Y. (2018, February). Virtual reality classroom applied to science 
education. In 2018 23rd International Scientific-Professional Conference on Information Technology, 1-4.

Ma, X., Cackett, M., Park, L., Chien, E., \& Naaman, M. (2018). Web-based VR experiments powered by the crowd. In Proceedings of the 2018 World Wide Web Conference, 33-43.

Martínez-Graña, A., González-Delgado, J., Pallarés, S., Goy, J., \& Llovera, J. (2014). 3D virtual itinerary for education using Google Earth as a tool for the recovery of the geological heritage of natural areas: Application in the "Las Batuecas Valley" nature park (Salamanca, Spain). Sustainability, 6(12), 8567-8591.

McCaffrey, K. J. W., Jones, R. R., Holdsworth, R. E., Wilson, R. W., Clegg, P., Imber, J., Holliman, N., \& Trinks, I. (2005). Unlocking the spatial dimension: digital technologies and the future of geoscience fieldwork. Journal of the Geological Society, 162(6), 927938.

Meagher, B. J., Cataldo, K., Douglas, B. J., McDaniel, M. A., \& Nosofsky, R. M. (2018). Training of rock classifications: The use of computer images versus physical rock samples. Journal of Geoscience Education, 66(3), 221-230.

Qiu, W., \& Hubble, T. (2002). The advantages and disadvantages of virtual field trips in geoscience education. The China Papers, 1, 75-79.

Stieff, M., Bateman, R. C., \& Uttal, D. H. (2005). Teaching and learning with three-dimensional representations. In Visualization in science education. Springer, Dordrecht, 93-120.

Welsh, K., \& France, D. (2012). Spotlight on... Smartphones and fieldwork. Geography, 97, 47.

Whitmeyer, S., Feely, M., De Paor, D., Hennessy, R., Whitmeyer, S., Nicoletti, J., Santangelo, B., Daniels, J., \& Rivera, M. (2009). Visualization techniques in field geology education: A case study from western Ireland. Field geology education: Historical perspectives and modern approaches, 461, 105.

\section{Biographical Statements}

Sukonmeth JITMAHANTAKUL is a senior lecturer in the Department of Geology at the Faculty of Sciences, Chulalongkorn University. His research focuses on geoscience education, innovative and inclusive teaching methods, and curriculum development.

Piyaphong CHENRAI is an assistant professor in the Department of Geology at the Faculty of Sciences, Chulalongkorn University. His research focuses on geoscience education, innovative and inclusive teaching methods, and curriculum development. 